\title{
Enhance mechanical properties of timber, engineered wood products and timber structures. Special Issue based upon work from COST Action FP1004, supported by COST (European Cooperation in Science and Technology)
}

\author{
Richard Harris ${ }^{1} \cdot$ Jan-Willem van de Kuilen ${ }^{2}$
}

Published online: 11 April 2016

(c) Springer-Verlag Berlin Heidelberg 2016

\begin{abstract}
This Introductory Paper sets the scene for this special edition of the European Journal for Wood and Wood Products, which contains papers selected to demonstrate and record aspects of the COST Action, achieved through networking and collaboration. The paper discusses the context of COST Action FP1004, showing how it seeks to benefit designers and builders of timber buildings as well as enhancing performance and thus delivering a benefit to society as a whole.
\end{abstract}

\section{Introduction}

Timber and wood based products are very important structural materials in modern construction; they offer the potential for cost efficient, high-quality sustainable construction. However, the adoption of modern engineered timber products, not only offers opportunities, it presents challenges that derive from timber's properties. Wood is a natural product and so, as a raw material for manufacture, it has more variation than products such as steel. In addition, wood is orthotropic and inhomogeneous, that is it has different and varying properties along and across its length and its properties are affected by moisture. For these reasons, there has been much recent research and development to create new wood-based products and techniques by enhancing the properties of wood and wood structures through reinforcement and by combining wood with other materials.

Richard Harris

r.harris@bath.ac.uk

Jan-Willem van de Kuilen

vandekuilen@hfm.tum.de

1 University of Bath, Bath, UK

2 Holzforschung München, TU München, Munich, Germany
Much recent research and development of modern products in wood has been aimed at enhancing predictability and reliability of timber structures, improving the mechanical performance of connections and reinforcing timber in weak zones. There has been research in these fields in Europe but the output has been fragmented both by geography and by language.

The challenge that this COST Action sets out to address was the bringing together of the strands of research in the field and the dissemination of knowledge amongst researchers and practitioners.

The COST Action has enabled existing research to be disseminated and existing understanding to be developed in new applications. Collaboration developed in the network of the COST Action has led to researchers working towards improved methods. The next generation of research engineers in the field has been encouraged through strong attention to involving Early Stage Researchers in the COST Action.

This special edition presents a set of papers that represent the scope of work contained within COST Action FP1004, which started in May 2010 and concluded with its final conference in April 2015. The MoU was signed by 27 countries and was joined by Australia, Canada and New Zealand as International Partner Countries.

This Introductory Paper sets out the scope of COST Action FP1004's activities and shows how it achieved a successful outcome.

\section{The beneficiaries and the success of the COST action programme}

A strict principle in the COST Action programme is that only expenses are reimbursed and the participants contribute their time for no fee. Thus, providing the activities 
are well managed and produce valuable output, society must surely be gaining excellent value for money. It is clear that, because the contributors were not funded to take part in the activities of the project, every event had to deliver strong benefits to both the individual participants and the wider timber engineering research community.

In the wider context, the main beneficiaries of better use of timber in building construction are the users of buildings - that is the whole of society. Through better understanding of modern methods and techniques, designers and builders are able to increase the use of wood in modern structures.

The increased use of wood has a positive environmental influence and contributes to the sustainable development of society, especially on issues related to global warming and renewable resources. Thus society benefits from wider use of this building material.

More particularly, the success of COST Action FP1004 is demonstrated in the scope of its activities. According to the EU Commission report, "A BLUEPRINT FOR THE EU FOREST-BASED INDUSTRIES"1, the EU woodworking industries employ over 1 million people. The sector is very significant in the EU economy generating an annual turnover of around $€ 122$ billion and an added value of over $€ 31$ billion. However, the industry is highly fragmented; there are some 1,84,000 companies and the European timber research sector is also separated between institutions. This COST project has taken the opportunity to draw the research community together to create an integrated network, which benefits the EU economy and industry as a whole.

\section{COST action instruments}

In delivering the COST Action, the funding allows the use of a range of "instruments". These are:

Meetings-conferences and seminars focussing on Work Group Topics.

Short Term Scientific Missions-short visits by researcher from and institution on one COST Action country to an institution in another COST Action country to enable collaboration.

Training Schools-delivered by COST Action participants as teachers to students from member countries of the COST Action.

In its life of 4 years, the COST Action organised two seminars and six conferences. Each conference was focused on a specific topic within the scope of the COST Action and published proceedings to enable the knowledge in the field to be set down and disseminated. The proceedings are freely available on the COST Action website http://costfp1004.holz.wzw.tum.de/hosted by the Holzforschung München of the Technical University of Munich. Thus COST Action FP1004 has both enhanced the scientific capabilities of researchers and built networks.

All of the conferences were excellently organised by their host institutions, were well attended by delegates from research and industry and included first-class presentations and papers.

Three of the conferences had a structural engineering perspective and dealt with specific topics, which were: Cross Laminated Timber (TU Graz, Graz, Austria), Timber Bridges (University of Applied Sciences, Biel, Switzerland) and Innovative Timber Composite structures (TTR Centre, Nicosia, Cyprus).

With respect to more fundamental issues, the University of Zagreb, Croatia organized an early stage researchers conference and the Czech Technical University in Prague, Czech Republic hosted a conference on Experimental Research on Wood.

Lund University in Sweden, the University of Trento in Italy and Edinburgh Napier University in UK organized training schools.

The Laboratório Nacional de Engenharia Civil (LNEC) organized the final conference, Lisbon in mid-2015; it formed the basis for this special issue of the European Journal of Wood and Wood Products.

The 4 years of this action are summarized in the figure below, comprising all activities in a single overview. 

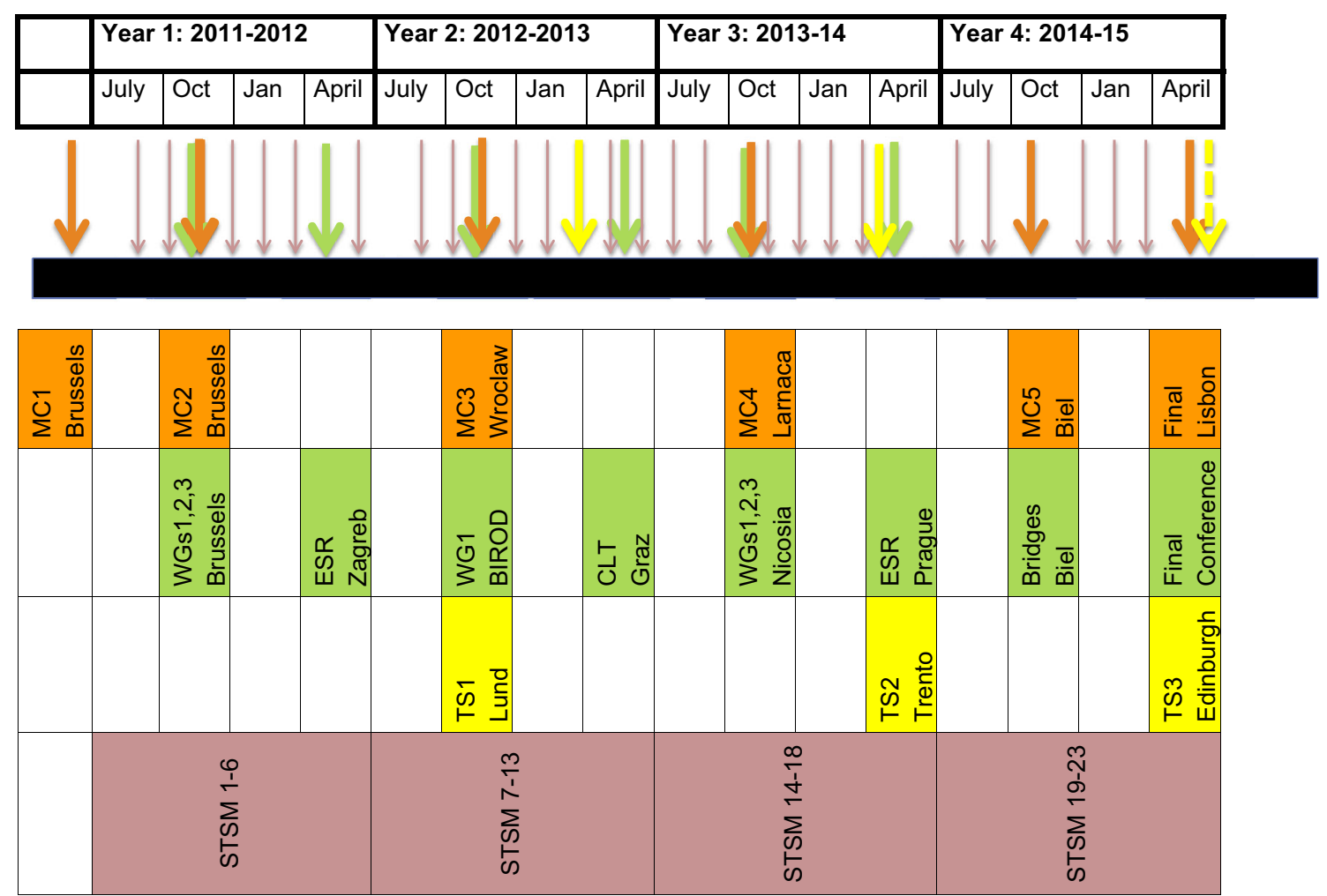

\section{Summary}

Timber engineering is vitally important to the sustainable development of society. However it lacks the research funding, both historically and in the present day, which has been available to its less sustainable competitors, notably steel and concrete. This is because the timber engineering sector is fragmented but steel and concrete have a large, well-established and close-knit research network, supported by a highly consolidated industry. This COST Action has made a small but important impact and those working in further COST Actions in this sector will build on its success in bringing together scientists across EU, facilitating collaboration across borders, creating new research alliances and generating new ideas. It has actively involved young scientists in international research activities and has minimised redundancies in research. It is hoped that it will leverages funds for new collaborative research. All this has been achieved through EU funds providing mechanisms and financial support as seed funding to facilitate the COST Action activities, with the bulk of the contribution coming from the organisers, speakers, conference hosts and delegates contributing their time for no fee.

Richard Harris,

Chairman of COST Action FP1004

Guest Editor

Jan-Willem van de Kuilen,

Editor 